\title{
Melting and Crystallization of Poly(ethylene adipate) under High Pressure
}

\author{
Chitoshi Nakafuku \\ Faculty of Education, Kochi University, Kochi 780-8072, Japan
}

(Received January 12, 1998)

\begin{abstract}
KEY WORDS Poly(ethylene adipate) / Melting / Crystallization / Differential Thermal Analysis / Differential Scanning Calorimetry / Wide Angle X-ray Diffraction / High Pressure /
\end{abstract}

\begin{abstract}
Pressure dependence of the melting temperature $\left(T_{\mathrm{m}}\right)$ of poly(ethylene adipate) (PEA), an aliphatic polyester of the molecule $\left(-\mathrm{O}-\left(\mathrm{CH}_{2}\right)_{2}-\mathrm{O}-\mathrm{CO}-\left(\mathrm{CH}_{2}\right)_{4}-\mathrm{CO}-\right)_{n}$, was reported by Ueberreiter et al. using high pressure DTA. ${ }^{1}$ They reported pressure change for only one melting temperature of PEA up to $500 \mathrm{MPa}$. In a recent study, we found two endothermic peaks around the melting region of PEA in differential scanning calorimetry (DSC). This short communication reports the melting behavior of PEA which shows double melting peak in the melting region and crystallization behavior up to $500 \mathrm{MPa}$. A high pressure crystallized sample was studied at $0.1 \mathrm{MPa}$ by wide angle X-ray diffraction (WAXD) measurement and DSC. The WAXD pattern of PEA changes with increasing crystallization pressure.
\end{abstract}

\section{EXPERIMENTAL}

The PEA raw material used in this study was purchased from Scientific Polymer Products, Inc. The molecular weight of PEA by GPC was 10000 (suppliers' data). Rod-like sample for high pressure DTA and X-ray diffraction measurement was prepared by cooling from the melt in a piston and cylinder $(1.8 \mathrm{~mm}$ in inside diameter) made of poly(tetrafluoroethylene).

High pressure DTA was performed using the apparatus described elsewhere. ${ }^{2}$ The rod-like sample of $1.8 \mathrm{~mm}$ in diameter was cut into pieces $1.8 \mathrm{~mm}$ in length and attached to a thermocouple junction in high pressure DTA plug and covered by epoxy resin. Heating rate of high pressure DTA was $6 \mathrm{~K} \mathrm{~min}^{-1}$. Cooling rate was about $4 \mathrm{~K} \mathrm{~min}^{-1}$.

The sample for WAXD measurement was prepared by wrapping tightly the rod-like sample (18 $\mathrm{mm}$ in length) with aluminum foil and covering the foil with epoxy resin. Crystallization of the sample under high pressure was performed as follows. After the sample was set in the DTA cell, pressure was applied. Then the cell was heated to a temperature $7-10^{\circ} \mathrm{C}$ higher than $T_{\mathrm{m}}$ determined by DTA. Heating rate and cooling rate were almost the same as that of high pressure DTA.

Rigaku 8230 D with TAS 200 control system was used for DSC measurement. A small sample cut from the rod was packed in an aluminum pan and measured in DSC. Heating rate was $6 \mathrm{Kmin}^{-1}$ and the cooling rate, $5 \mathrm{~K} \min ^{-1}$.

WAXD pattern was obtained with a rod-like sample of $1.8 \mathrm{~mm} \phi$ formed by cooling from the melt under pressure and $0.1 \mathrm{MPa}$. Nickel filtered $\mathrm{Cu}-K_{\alpha}$ radiation was used as an incident X-ray beam. In the WAXD measurement during heating, a heating device made at this laboratory was used on the goniometer.

\section{RESULTS AND DISCUSSION}

Figure 1 shows the DSC curve of melting for the sample crystallized at $0.1 \mathrm{MPa}$ and $500 \mathrm{MPa}$ from the melt. A large endothermic peak was observed at $48.8^{\circ} \mathrm{C}$ and a shoulder at $40.1^{\circ} \mathrm{C}$ for the sample crystallized at $0.1 \mathrm{MPa}$. On the other hand, two endothermic peaks are observed at $38.9^{\circ} \mathrm{C}$ and $49.2^{\circ} \mathrm{C}$ in the sample crystallized at $500 \mathrm{MPa}$. High pressure crystallization of PEA increased the formation of crystals corresponding to the low temperature peak of melting.

Pressure change of the DTA heating and cooling curve was obtained up to $500 \mathrm{MPa}$. An endothermic double peak was observed up to $500 \mathrm{MPa}$ in the DTA curve of melting. The intensity of the low temperature peak decreased slightly with pressure but remained at 500 $\mathrm{MPa}$. The distance between two peaks increased with pressure. Exothermic peak of crystallization was observed in the cooling process up to $500 \mathrm{MPa}$. Figure 2 shows pressure dependence of the high temperature peak and low temperature peak of melting and the crystallization peak temperature $\left(T_{\mathrm{c}}\right)$ in cooling process. The melting curves ( $T_{\mathrm{m}}$ versus pressure curve) and crystallization curve ( $T_{\mathrm{c}}$ versus pressure curve) are fitted to a quadratic equation of the form, $T_{\mathrm{m}}=A+B P-C P^{2}$, where $P$ is the pressure. The coefficients $A, B$, and $C$ are

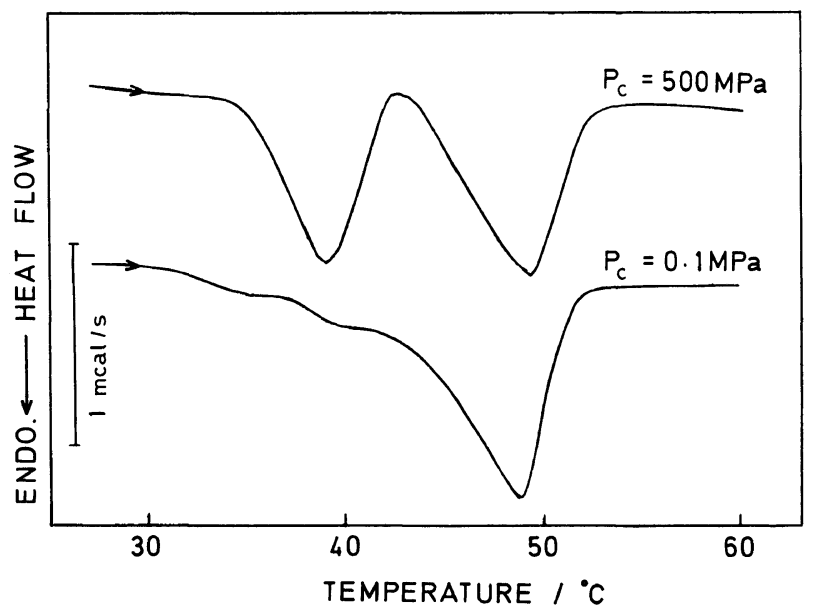

Figure 1. DSC curve of melting for PEA sample crystallized at 0.1 $\mathrm{MPa}$ and $500 \mathrm{MPa}$. 


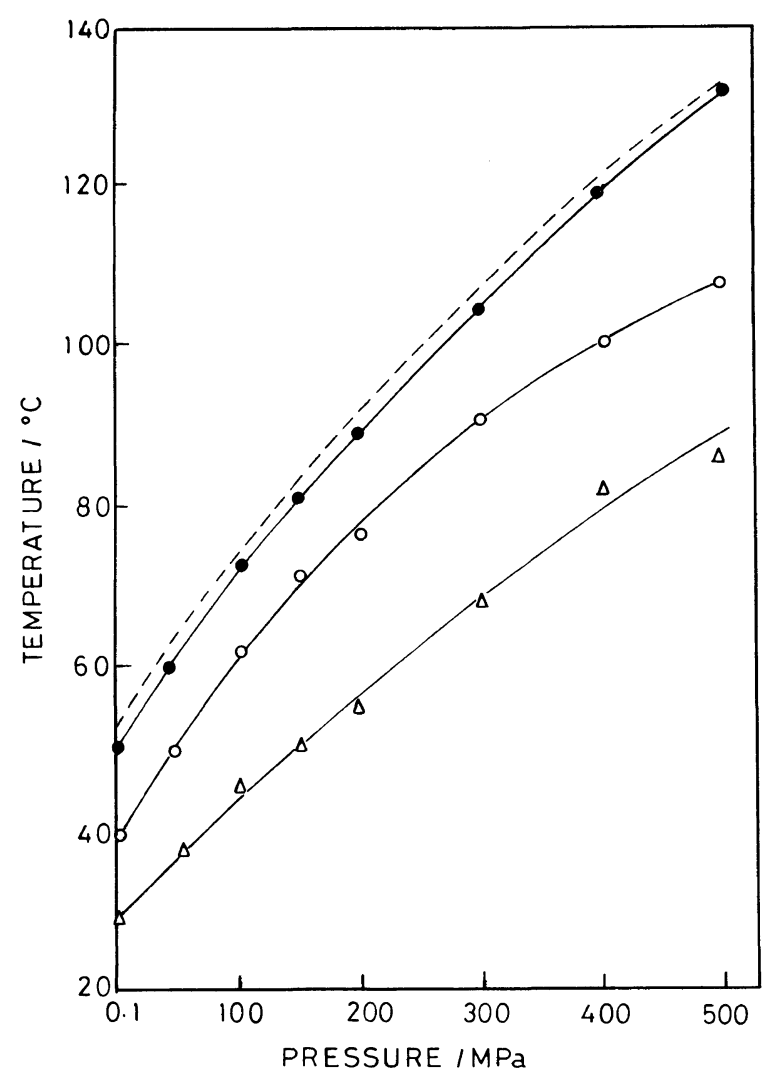

Figure 2. Pressure dependence of $T_{\mathrm{mh}}, T_{\mathrm{ml}}$, and $T_{\mathrm{c}}$ of PEA.,$T_{\mathrm{mh}}$; O, $T_{\mathrm{ml}} ; \Delta, T_{\mathrm{c}} ;-\cdots---$, Ueberreiter et al. ${ }^{1}$

Table I. Values of $A, B$, and $C$ determined in the equation $T_{\mathrm{m}}, T_{\mathrm{c}}=A+B P-C P^{2}$ for the melting and crystallization temperatures of PEA

\begin{tabular}{|c|c|c|c|}
\hline & $A$ & $B$ & C \\
\hline & ${ }^{\circ} \mathrm{C}$ & $\mathrm{KMPa}^{-1}$ & $\times 10^{-4} \mathrm{KMPa}^{-2}$ \\
\hline$T_{\mathrm{mh}}$ & 50.8 & 0.214 & 1.08 \\
\hline$T_{\mathrm{m}}$ & 40.1 & 0.223 & 1.79 \\
\hline$T_{\mathrm{c}}$ & 29.1 & 0.156 & 0.777 \\
\hline
\end{tabular}

determined by the least square's method. ${ }^{3}$ Table I lists the values of $A, B$, and $C$ for the three curves. Melting curve of the high temperature peak was very close to the curve reported by Ueberreiter et al. ${ }^{1}$ as shown in Figure 2.

Temperature change of the X-ray diffraction pattern at $0.1 \mathrm{MPa}$ was studied up to above $T_{\mathrm{m}}$ of PEA but no evidence was shown suggesting crystal structure change below the melting temperature as shown in Figure 3. The crystal unit cell of PEA is monoclinic and diffraction peaks from (111), (110), and (020) are observed at $20.4^{\circ}$, $21.5^{\circ}$, and $24.8^{\circ}$ in $2 \theta$. Very small peak like change appeared at around $18.5^{\circ}\left(20^{\circ} \mathrm{C}\right.$ and $\left.30^{\circ} \mathrm{C}\right)$ and $19.5^{\circ}$ $\left(52^{\circ} \mathrm{C}\right)$ is not diffraction peak because no peaks exist at the angle in the calculation using the lattice constant reported by Turner-Jones and Bunn. ${ }^{4}$ Small peak like noise was also observed at the top curve (molten state) in the figure. At $41^{\circ} \mathrm{C}$ and $45^{\circ} \mathrm{C}$, just above the low temperature peak in DSC curve, the diffraction peak only slightly decreased in intensity. Inclination of the curve of low temperature peak decreased with pressure especially above $400 \mathrm{MPa}$. This means that the high

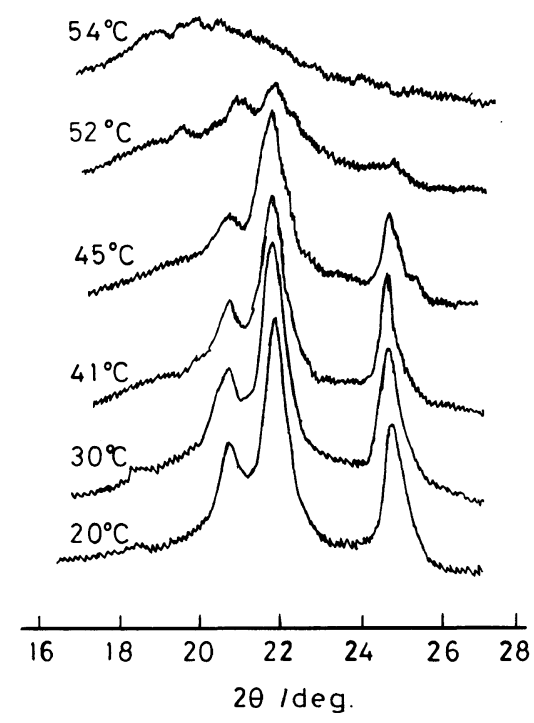

Figure 3. Temperature change of WAXD curve of PEA sample.

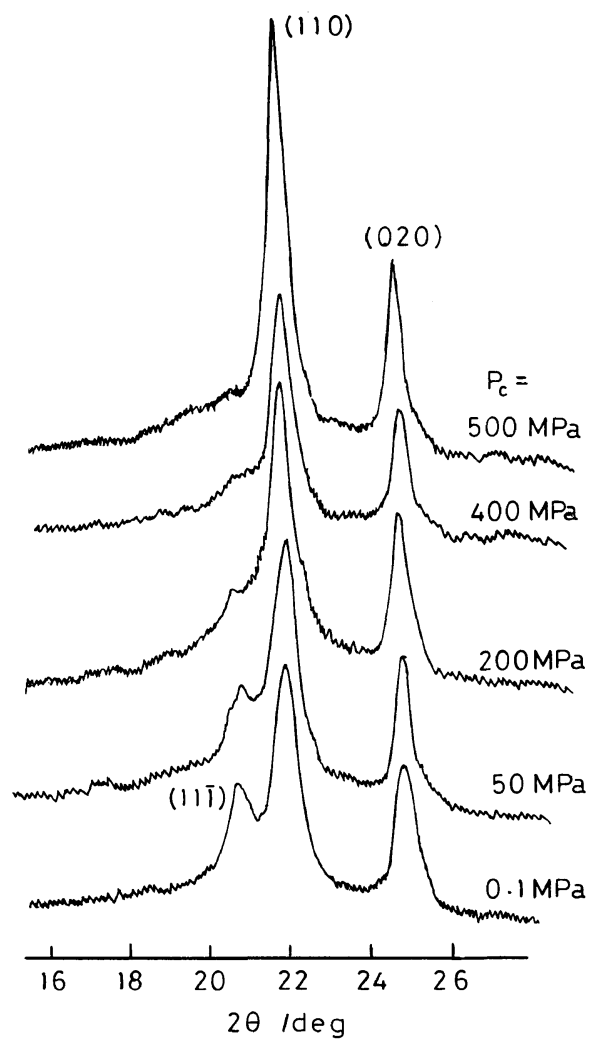

Figure 4. WAXD curve of PEA sample crystallized at $0.1 \mathrm{MPa}$ and under high pressure.

temperature peak is pressure sensitive and the low temperature peak is due to the melting of small crystals or imperfect crystals containing many defects in it.

Al-Raheil and Qudah ${ }^{5}$ reported that three endothermic peaks appeared in melting of another aliphatic polyester, poly(ethylene succinate) (PES) with the molecular structure $-\left(\mathrm{O}-\left(\mathrm{CH}_{2}\right)_{2}-\mathrm{O}-\mathrm{CO}-\left(\mathrm{CH}_{2}\right)_{2}-\mathrm{CO}-\right)_{n}$. The middle temperature peak was due to the melting of primary lamellae formed in the crystallization process and the low temperature peak was due to the melting of subsidiary lamellae formed after crystallization of primary lamellae. The high temperature peak was due to the melting of re-crystallized lamellae formed in the 
heating process. In the case of PEA, the high temperature peak appeared for all the samples crystallized from the melt, so that it is due to the melting of the primary crystals formed during cooling. Spherulite was not observed in the PEA sample crystallized from the melt by optical microscopic observation. Small crystals appeared in the sample crystallized at $1.0 \mathrm{MPa}$ and $450 \mathrm{MPa}$.

WAXD pattern of the sample crystallized under high pressure is shown in Figure 4. Diffraction peak from (110) and (020) was observed for the sample crystallized under pressure from $0.1 \mathrm{MPa}$ to $500 \mathrm{MPa}$. On the other hand, the diffraction peak from $(11 \overline{1})$ at $20.4^{\circ}$ in $2 \theta$ decreased in intensity with increasing crystallization pressure. This indicates that in the high pressure crystallized sample, the crystalline order along $c$-axis direction decreased with increasing pressure though the order for $a$ - and $b$-axis direction did not change. Such disorder in $c$-axis direction may induce many defects in the crystal and lowering the melting temperature. The low temperature peak in DSC may be due to melting of the imperfect crystals formed in the cooling process. Crystallization during cooling under high pressure above $200 \mathrm{MPa}$ of PEA formed this type of imperfect crystals as appeared in the low temperature peak in Figure 1.

\section{REFERENCES}

1. K. Ueberreiter, V.-K. Karl, and A. Altmeyer, Eur. Polym. J., 14, 1045 (1978)

2. C. Nakafuku, Polym. J., 26, 680 (1994).

3. C. Nakafuku, Polym. J., 27, 917(1995).

4. A. Turner-Jones and C. W. Bunn, Acta Crys., 15, 105 (1962)

5. I. A. Al-Raheil and A. M. A. Qudah, Polym. Int., 37, 249 (1995). 